\title{
Synchronous fluorescence spectrofluorimetric method for the simultaneous determination of metoprolol and felodipine in combined pharmaceutical preparation
}

\author{
Mohamed I Walash, Fathallah F Belal, Nahed M El-Enany ${ }^{*}$ and Mahmoud H El-Maghrabey
}

\begin{abstract}
A rapid, simple and sensitive synchronous specrtofluorimetric method has been developed for the simultaneous analysis of binary mixture of metoprolol (MTP) and felodipine (FDP). The method is based upon measurement of the synchronous fluorescence intensity of the two drugs at $\Delta \lambda$ of $70 \mathrm{~nm}$ in aqueous solution. The different experimental parameters affecting the synchronous fluorescence intensities of the two drugs were carefully studied and optimized. The fluorescence intensity-concentration plots were rectilinear over the ranges of $0.5-10 \mu \mathrm{g} / \mathrm{mL}$ and $0.2-2 \mu \mathrm{g} / \mathrm{mL}$ for MTP and FDP, respectively. The limits of detection were 0.11 and $0.02 \mu \mathrm{g} / \mathrm{mL}$ and quantification limits were 0.32 and $0.06 \mu \mathrm{g} / \mathrm{mL}$ for MTP and FDP, respectively. The proposed method was successfully applied for the determination of the two compounds in their commercial tablets and the results obtained were favorably compared to those obtained with a comparison method.
\end{abstract}

\section{Introduction}

Felodipine (FDP), Ethyl methyl 4-(2, 3-dichlorophenyl)1, 4-dihydro-2, 6-dimethylpyridine-3, 5-dicarboxylate (Figure 1a) is a dihydropyridine calcium-channel blocker. It is used in the management of hypertension and angina pectoris [1]. Metoprolol (MTP), ( \pm )-1-Isopropylamino-3-[4-(2-methoxyethyl)phenoxy]propan-2-ol (Figure $1 \mathrm{~b}$ ), is a cardio-selective $\beta$ blocker. It has been reported that MTP lacks intrinsic sympathomimetic activity and has little or no membrane-stabilizing activity. It is mainly used in the treatment of hypertension, angina pectoris, cardiac arrhythmias, myocardial infarction, and heart failure. It is also used in the management of hyperthyroidism and in the prophylactic treatment of migraine [1].

Both drugs are official in the United States Pharmacopoeia (USP, 2). The USP [2] recommended HPLC methods for the determination of each of FDP and MTP in pure form and in different dosage forms. Since the combined therapy of FDP and MTP has been clinically

\footnotetext{
* Correspondence: nelenany1@yahoo.com

Department of Pharmaceutical Analytical Chemistry, Faculty of Pharmacy, University of Mansoura, 35516, Mansoura, Egypt
}

proven to be significantly efficient in the treatment of hypertension, it became important to develop and validate a reliable method for the separation and determination of the two drugs in their commercially available formulations. Only few methods have been reported in the literature for the assay of such mixture, using chemometric assisted spectrophotometric methods [3,4] and HPLC methods [3-5].

Only one spectrofluorimetric method has been developed for the analysis of MTP in human plasma using trilinear decomposition-based techniques [6]. Regarding FDP, a convential fluorimetric method was reported for its determination in presence of ramipril in their combined tablets Triacor $^{\mathbb{B}}$ [7].

To the best of our knowledge, neither conventional nor synchronous spectrofluorimetry has been reported for the analysis of MTP and FDP in their binary mixtures.

The normal excitation fluorescence spectra of MTP and FDP are greatly overlapped. This observation led us to utilize synchronous fluorescence spectroscopy (SFS) to solve such problem by measuring Synchronous 
<smiles>CCOC(=O)C1=C(C)NC(C)=C(C(=O)OC)C1c1cccc(Cl)c1Cl</smiles>

(a)<smiles>COCCc1ccc(OCC(O)CNC(C)C)cc1</smiles>

(b)

Figure 1 Structural formulae of the studied drugs. Where: (a) Felodipine (FDP), (b) Metoprolol (MTP).

Fluorescence Intensities (SFI) at 260 and $375 \mathrm{~nm}$ for MTP and FDP respectively.

Based on chemical features of both drugs, and high therapeutic effect of MTP and FDP combined in treatment of hypertension, the (SFS) technique was developed for the simultaneous determination of both drugs in their combined tablets.

Synchronous fluorescence spectroscopy (SFS) has several advantages over conventional fluorescence spectroscopy, including simple spectra, high selectivity and low interference [8]. Because of its sharp, narrow spectrum, SFS serves as a very simple, effective method for achieving data for quantitative determination in a single run [9].

\section{Experimental \\ Material}

- Metoprolol tartrate pure sample was kindly provided by Sigma company.

- Felodipine pure sample was kindly provided by Minapharm.

- Logimax ${ }^{\circledR}$ tablets labeled to contain $50 \mathrm{mg}$ of MTP and $5 \mathrm{mg}$ of FDP (Batch \# 90015) were obtained from commercial source in the local market.

\section{Reagents}

All reagents and solvents used were of Analytical Reagent Grade.

- Methanol (Merck, Darmstadt, Germany).

- Acetic acid, Sodium acetate and Boric acid (BDH, UK).

- Acetate buffer $0.2 \mathrm{M}$ (pH 4.5) was prepared by mixing appropriate volume of $0.2 \mathrm{M}$ acetic acid with $0.2 \mathrm{M}$ sodium acetate. Borate buffers ( $\mathrm{pH} 8.5)$ were prepared by mixing appropriate volumes of $0.02 \mathrm{M}$ boric acid with $0.2 \mathrm{M}$ sodium hydroxide.

- Sodium hydroxide ((BDH, UK), 0.1 M aqueous solution was freshly prepared.

\section{Apparatus}

Fluorescence spectra and measurements were recorded using a Perkin-Elmer UK model LS 45 luminescence spectrometer, equipped with a 150 Watt Xenon arc lamp, gratting excitation and emission monochromators for all measurements and a Perkin-Elmer recorder. Slit widths for both monochromators were set at $10 \mathrm{~nm}$. A $1 \mathrm{~cm}$ quartz cell was used. The SF spectra were estimated at $260 \mathrm{~nm}$ and $375 \mathrm{~nm}$ for MTP and FDP, respectively.

A Consort NV P901 digital pH Meter (Belgium) calibrated with standard buffers was used for checking the $\mathrm{pH}$ of the buffer solutions used.

\section{Standard Solutions}

Stock solutions of MTP and FDP were prepared by dissolving $10.0 \mathrm{mg}$ of the studied compounds in $100 \mathrm{~mL}$ of methanol in a calibrated flask and were further diluted

Table 1 Performance data of the determination of MTP and FLD in pure form by the proposed method

\begin{tabular}{ccc}
\hline Parameter & Metoprolol & Felodipine \\
\hline Concentration range $(\mu \mathrm{g} / \mathrm{mL})$ & $0.5-10.0$ & $0.2-2.0$ \\
Correlation coefficient & 0.9999 & 0.9999 \\
Slope & 56.36 & 164.51 \\
Intercept & 11.12 & 7.15 \\
Limit of detection $(\mathrm{LOD})(\mu \mathrm{g} / \mathrm{mL})$ & 0.11 & 0.02 \\
Limit of Quantification $(\mathrm{LOQ})(\mu \mathrm{g} / \mathrm{mL})$ & 0.32 & 0.06 \\
$\mathrm{~S}_{\mathrm{y} / \mathrm{x}}$ & 2.87 & 1.31 \\
$\mathrm{~S}_{\mathrm{a}}$ & 1.82 & 0.91 \\
$\mathrm{~S}_{\mathrm{b}}$ & 0.33 & 0.91 \\
$\% \mathrm{RSD}$ & 1.49 & 1.17 \\
$\%$ Er & 0.61 & 0.48
\end{tabular}

$\mathrm{S}_{\mathrm{y} / \mathrm{x}}$ Standard deviation of the residuals;

$\mathrm{S}_{\mathrm{a}}$, Standard deviation of the intercept

$\%$ RSD = Relative standard deviation;

$\mathrm{S}_{\mathrm{b}}$, Standard deviation of the slope

$\%$ Error $=\%$ RSD $/ \sqrt{ } \mathrm{n}$.

$\mathrm{n}=6$. 
with water to obtain standard solutions containing 10 $\mu \mathrm{g} / \mathrm{mL}$ of each drug. FDP standard solution was protected from light due to its photosensitivity. The standard solutions were stable for 10 days when kept in the refrigerator.

\section{Recommended procedures \\ Calibration Curves}

Aliquots of MTP and FDP standard solutions covering the working concentration range cited in table 1 were transferred into a series of $10 \mathrm{~mL}$ volumetric flasks. Then the solutions were diluted to volume with distilled water and mixed well. Synchronous fluorescence spectra of the solutions were recorded by scanning both monochromators at a constant wavelength difference $\Delta \lambda=70$ $\mathrm{nm}$ and scan rate of $600 \mathrm{~nm} / \mathrm{min}$ using $10 \mathrm{~nm}$ excitation and emission windows. The intensities of the SF spectra were estimated at $260 \mathrm{~nm}$ and $375 \mathrm{~nm}$ for MTP and FDP, respectively. A blank experiment was performed simultaneously. The relative fluorescence intensity of the synchronous spectra was plotted $v s$. the final concentration of the drugs $(\mu \mathrm{g} / \mathrm{mL})$ to get the calibration Curves. Alternatively, the corresponding regression equations were derived.

\section{Procedure for the synthetic mixture}

Aliquots of MTP and FDP standard solutions in the ratio of 10:1 were transferred into a series of $10 \mathrm{~mL}$ volumetric flasks. Then the solution was diluted to the volume with distilled water, and mixed well. The recommended procedure under Calibration Curve was then performed. The relative SF intensities were measured and the corresponding concentrations were derived from the calibration curves or the corresponding regression equations.

\section{Procedure for commercial tablets}

The films of ten coated (individually weighed) tablets were gently removed with water. The tablets were then dried, weighed, powdered and mixed well. A weighed quantity of the powder equivalent to $10.0 \mathrm{mg}$ MTP and $1 \mathrm{mg}$ of FDP (in their ratio of 10:1) was transferred into a small conical flask and extracted with 50 $\mathrm{mL}$ of methanol by ultrasonication for $30 \mathrm{~min}$. The extract was filtered with acrodisc GHP (Gelman Hydrophilic Polypropy lene membrane) into a $100 \mathrm{~mL}$ volumetric flask. The conical flask was washed with few mLs of methanol. The washings were passed into the same volumetric flask and completed to the mark with the same solvent.

Aliquots covering the working concentration range were transferred into $10 \mathrm{~mL}$ volumetric flasks. The recommended procedure under "Calibration Curve" was performed. The nominal content of the Tablets were determined either from a previously plotted calibration curve or using the corresponding regression equation.

\section{Results and discussion}

Synchronous fluorescence spectra of MTP and FDP

Metoptolol was found to exhibit two excitation wavelengths at 225 and $275 \mathrm{~nm}$, and two emission spectra at 306 and $460 \mathrm{~nm}$ (Figure 2). felodipine was found to exhibit maximum fluorescence intensity at $440 \mathrm{~nm}$ after excitation at 225, 240 and $375 \mathrm{~nm}$ (Figure 2). The emission spectra of both MTP and FDP greatly overlapped (Figure 3). This fact hindered the use of direct measurement for the simultaneous determination of MTP and FDP. This problem is more aggravated if it is desired to determine these compounds in their co-formulated preparations

It was necessary to record first the normal synchronous spectra for both MTP and FDP. There is no overlap between them after subtracting the value of the blank. Figure 4 shows the SF spectra of different concentrations of MTP at $260 \mathrm{~nm}$ in presence of constant concentration of FDP $(1.0 \mu \mathrm{g} / \mathrm{mL})$ and the blank synchronous spectra, whereas, Figure 5 illustrates the SF spectra of different concentrations of FDP at $375 \mathrm{~nm}$ in presence of constant concentration of MTP $(10.0 \mu \mathrm{g} /$ $\mathrm{mL}$ ) and the blank synchronous spectra.

\section{Optimization of experimental conditions}

Different experimental parameters affecting the performance of the proposed method were carefully studied and optimized. Such factors were changed individually

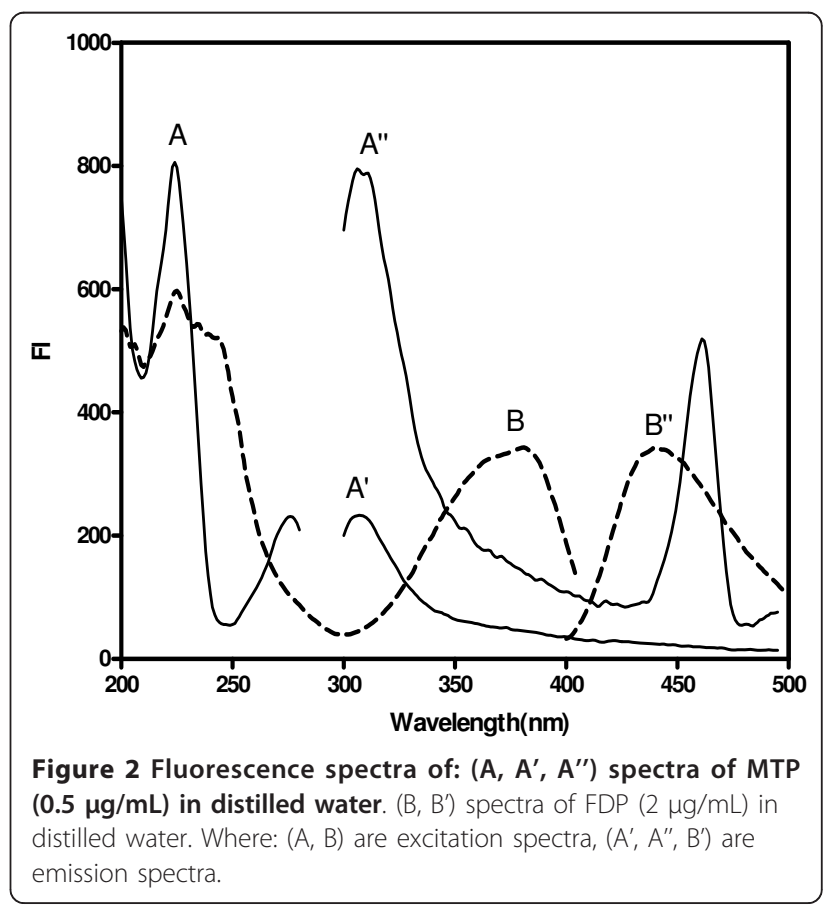



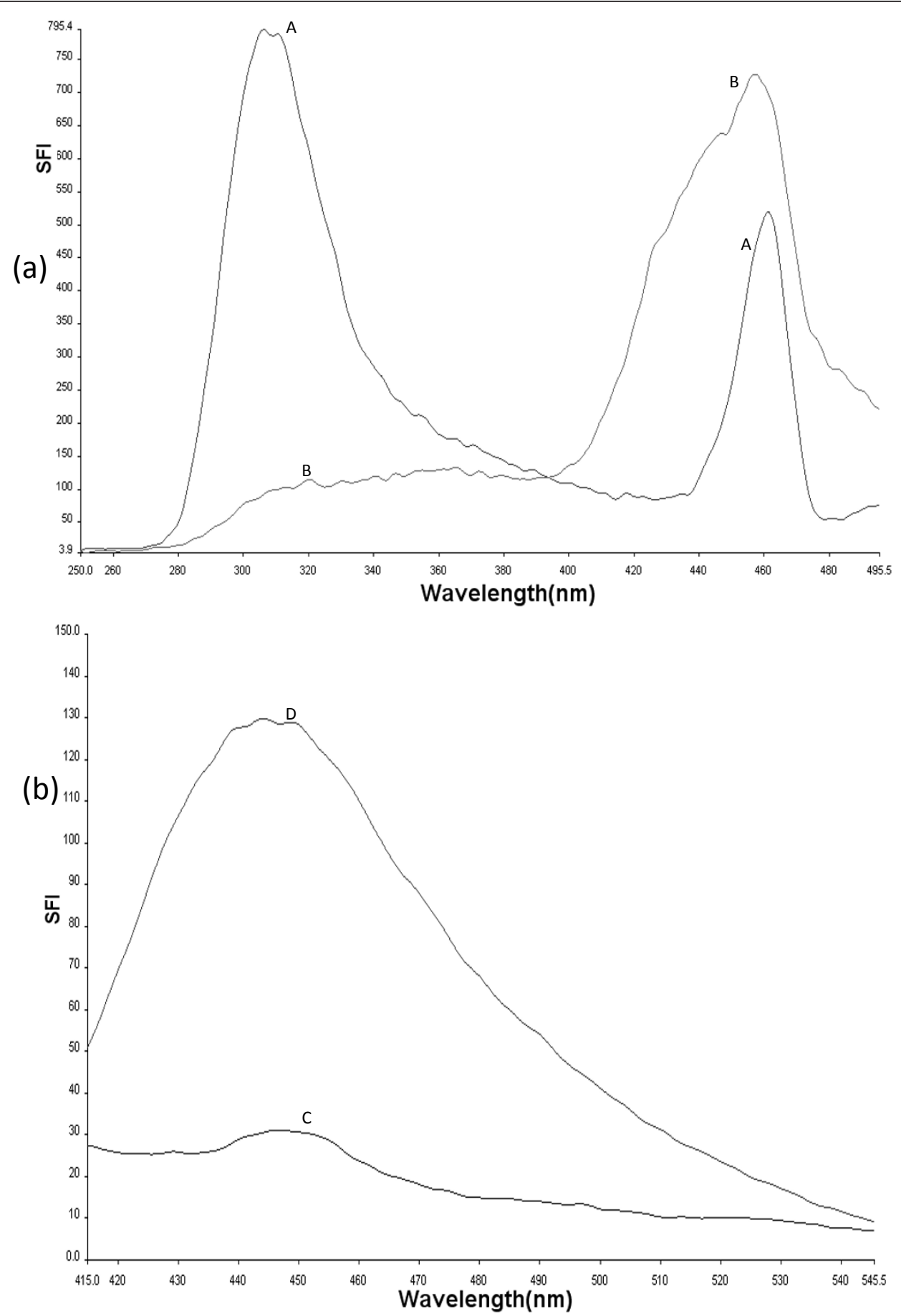

Figure 3 Emission fluorescence spectra of MTP and FDP. a: (A, B) spectra of MTP and FDP, respectively, after excitation at 225. b: (C, D) spectra of MTP and FDP, respectively, after excitation at 375.

while others were kept constant. These factors included: $\Delta \lambda, \lambda$ max, $\mathrm{pH}$ and type of the diluting solvent.

\section{Selection of optimum $\Delta \lambda$}

The optimum $\Delta \lambda$ value is an essential factor for performing the synchronous fluorescence scanning technique with regards to its resolution, sensitivity and features. It can directly influence spectral shape, band width and signal value. For this reason a wide range of $\Delta \lambda(20,40,60,70,80,100$ and $120 \mathrm{~nm})$ was examined (Figure 6). For MTP, when $\Delta \lambda$ was higher than $70 \mathrm{~nm}$, the fluorescence intensity was less sensitive while if $\Delta \lambda$ 


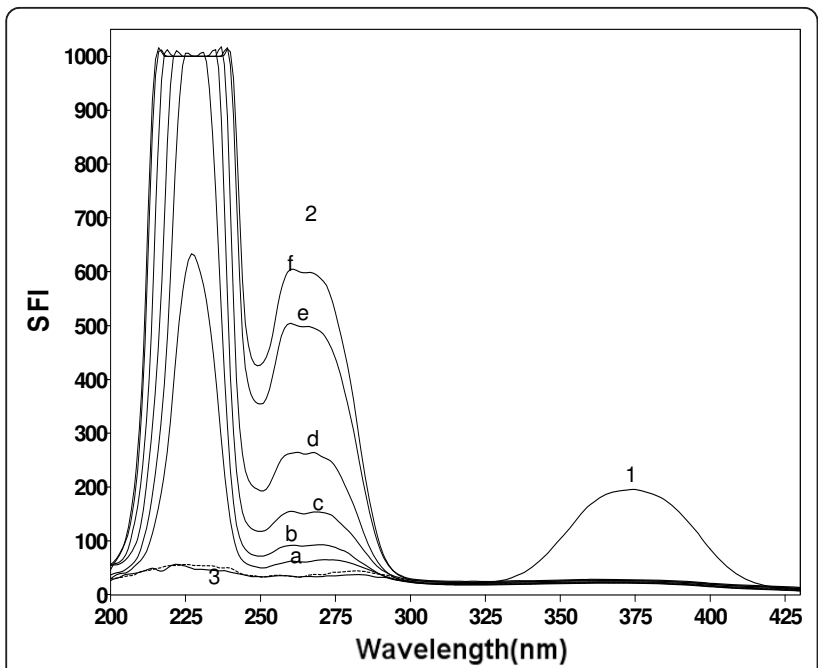

Figure 4 Synchronous fluorescence spectra of. (1) FDP $(1 \mu \mathrm{g} /$ $\mathrm{mL})$. (2) a-f, MTP $(0.5,1,2,4,8$ and $10 \mu \mathrm{g} / \mathrm{mL})$. (3) blank

was less than $70 \mathrm{~nm}$ the fluorescence intensity was very high and didn't enabled the simultaneous determination of the studied drugs in their pharmaceutical ratio (10 MTP: 1 FDP). For FDP, when $\Delta \lambda$ was less than $70 \mathrm{~nm}$, the fluorescence intensity was less sensitive while if $\Delta \lambda$ was $70 \mathrm{~nm}$ or higher it gave nearly the same sensitivity. Therefore, $\Delta \lambda$ of $70 \mathrm{~nm}$ was chosen as optimal one for separation of MTP and FDP mixtures, since it eliminated the spectral interference caused by each compound in the mixture and gave the desired sensitivity.

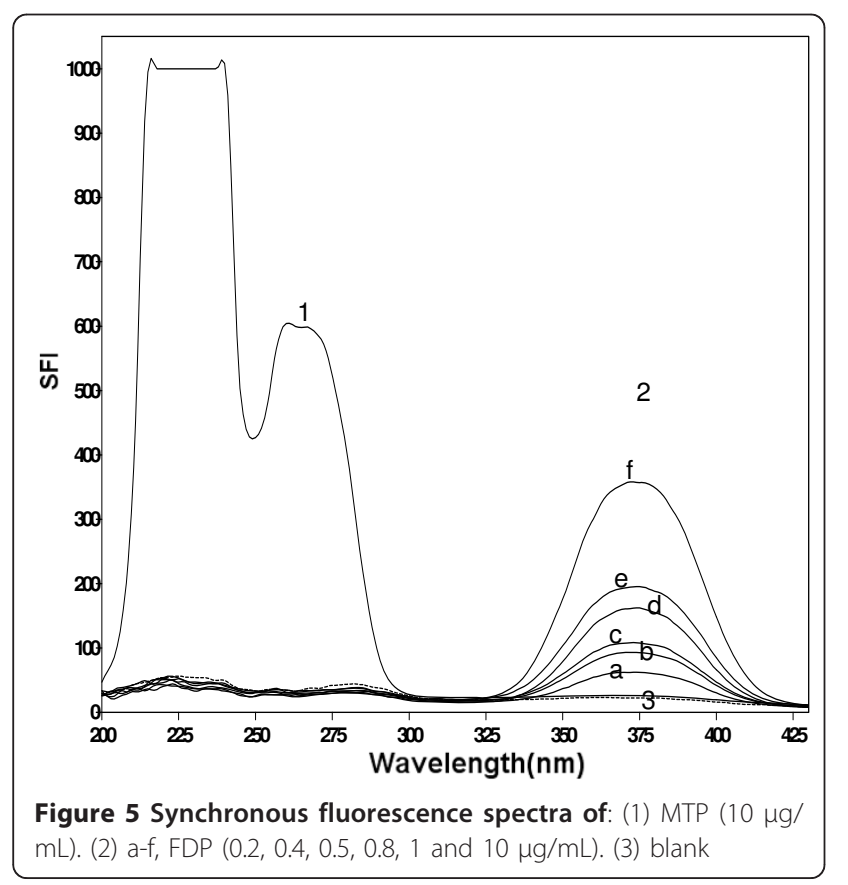

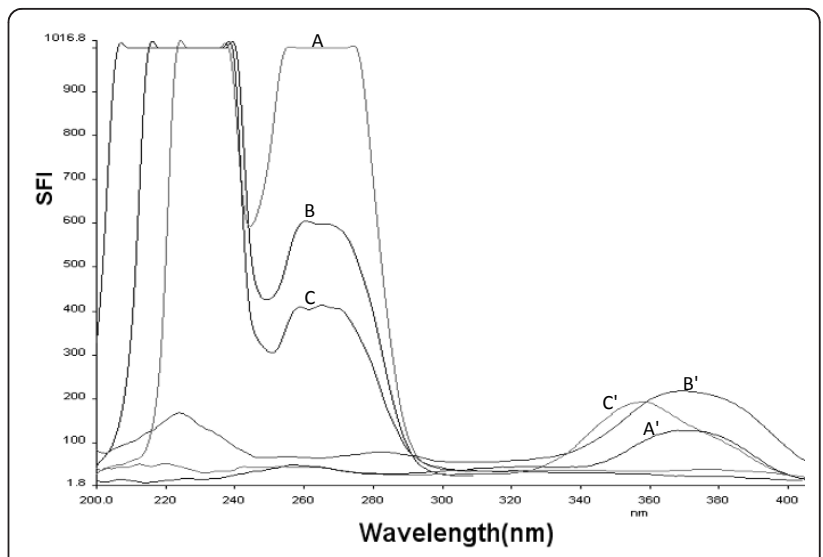

Figure 6 Synchronous fluorescence spectra of MTP and FDP at different $\Delta \lambda$. Where: (A, B and C) for MTP at $\Delta \lambda$ of 60,70 and 80 $n m$, respectively. ( $A^{\prime}, B^{\prime}$ and $C^{\prime}$ ) for FDP at $\Delta \lambda$ of 60,70 and $80 \mathrm{~nm}$, respectively.

Selection of appropriate $\lambda_{\max }$

Metoprolol SF spectra using $\Delta \lambda$ of 70 have two values of $\lambda_{\text {max }}$, one at 233 and the other at $260 \mathrm{~nm}$. The one at $260 \mathrm{~nm}$ didn't afford the higher sensitivity, yet it was used because it enabled the determination of FDP \& MTP simultaneously at the ratio of 1:10.

\section{Selection of optimum $\mathrm{pH}$}

The influence of $\mathrm{pH}$ on the fluorescence intensity of the two drugs was studied using different buffers covering the whole $\mathrm{pH}$ range, e.g. acetate buffer ( $\mathrm{pH}$ 3.6-5.6) and borate buffer $\mathrm{pH}$ (6-9.5). It was found that, using any of these two buffers either does not affect the synchronous fluorescence intensity or even decrease it. Therefore, for simplicity of the method no buffer was used throughout the study.

\section{Effect of diluting solvent}

Dilution with different solvents including; water, methanol, acetone, acetic acid, acetonitrile, dimethyl sulfoxide (DMSO), and dimethyl formamide (DMF) was employed (Figure 7). Water only gave the highest relative synchronous fluorescence intensity for MTP and FDP compared with the other solvents. Thus, water was chosen as the diluting solvent throughout the study.

\section{Validation of the Method}

The validity of the method was tested regarding; linearity \& range, accuracy, repeatability, precision and specificity according to ICH Q2B recommendations [10].

\section{Linearity and Range}

The regression plots showed a linear dependence of RSFI values on drug concentration over the range cited in Table 1. 


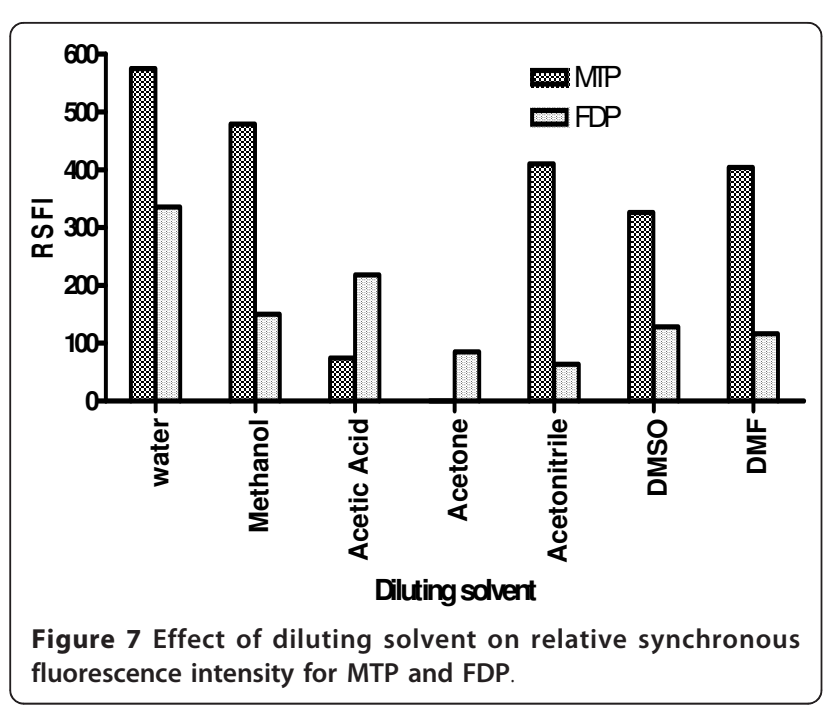

The validity of the methods was proved by statistical evaluation of the regression lines, using the standard deviation of the residuals $\left(\mathrm{S}_{\mathrm{y} / \mathrm{x}}\right)$, the standard deviation of the intercept $\left(\mathrm{S}_{\mathrm{a}}\right)$ and standard deviation of the slope $\left(\mathrm{S}_{\mathrm{b}}\right)$. The results are abridged in Table 1 . The small values of the figures point out to the low scattering of the points around the calibration curves and high precision.
Limit of quantification (LOQ) and limit of detection (LOD) The limit of quantification (LOQ) was determined by establishing the lowest concentration that can be measured according to ICH Q2B recommendations [10], below which the calibration graph is non linear. The limit of detection (LOD) was determined by evaluating the lowest concentration of the analyte that can be readily detected. The results of LOD and LOQ of MTP and FDP by SDSFS method are abridged in Table 1.

LOQ and LOD were calculated according to ICH Q2B recommendations [10]:

$$
\begin{aligned}
& \mathrm{LOQ}=10 \sigma / \mathrm{S} \\
& \mathrm{LOD}=3.3 \sigma / \mathrm{S}
\end{aligned}
$$

Where: $\mathrm{S}$ is the slope and $\sigma$ is the standard deviation of the intercept of regression line of the calibration curve.

\section{Accuracy and precision}

The proposed methods were applied to the determination of authentic samples of MTP and FDP over the concentration ranges cited in Table 2 in order to evaluate their accuracy. The results obtained were in good agreement with those obtained using comparison method [4]. Using the Student's t-test and the variance ratio F-test, [11] revealed no significant difference between the performance of the two methods regarding the accuracy and precision, respectively (Table 2).

\begin{tabular}{|c|c|c|c|c|}
\hline Parameters & Concentration taken $(\mu \mathrm{g} / \mathrm{mL})$ & Concentration found $(\mu \mathrm{g} / \mathrm{mL})$ & $\%$ Found & Comparison method (4) \\
\hline \multirow[t]{6}{*}{ 1-MTP } & 0.5 & 0.509 & 101.80 & 98.73 \\
\hline & 1.0 & 1.015 & 101.5 & 101.84 \\
\hline & 2.0 & 2.009 & 100.45 & 99.28 \\
\hline & 4.0 & 3.927 & 98.18 & \\
\hline & 8.0 & 8.051 & 100.64 & \\
\hline & 10.0 & 9.984 & 99.84 & \\
\hline$x$ & & & 100.40 & 99.95 \\
\hline SD & & & \pm 1.3 & \pm 1.66 \\
\hline t-test & & $0.45(2.36)$ & & \\
\hline F value & & $1.63(5.79)$ & & \\
\hline \multirow[t]{6}{*}{ 2-FDP } & 0.2 & 0.202 & 101.12 & 101.33 \\
\hline & 0.4 & 0.395 & 98.69 & 98.24 \\
\hline & 0.5 & 0.492 & 98.43 & 100.66 \\
\hline & 0.8 & 0.807 & 100.89 & \\
\hline & 1.0 & 1.008 & 100.78 & \\
\hline & 2.0 & 1.996 & 99.80 & \\
\hline$x$ & & & 99.95 & 100.08 \\
\hline SD & & & \pm 1.17 & \pm 1.63 \\
\hline t-test & & $0.13(2.36)$ & & \\
\hline F value & & $1.3(5.79)$ & & \\
\hline
\end{tabular}

Table 2 Application of the synchronous fluorimetry to the determination of the studied drugs in the pure form

Figures between parenthesis are the tabulated $t$ (at degree of freedom $=7$ for both drugs) and $F$ values (at degree of freedom $=2,5$ for both drugs), respectively at $\mathrm{p}=0.05[11]$. 


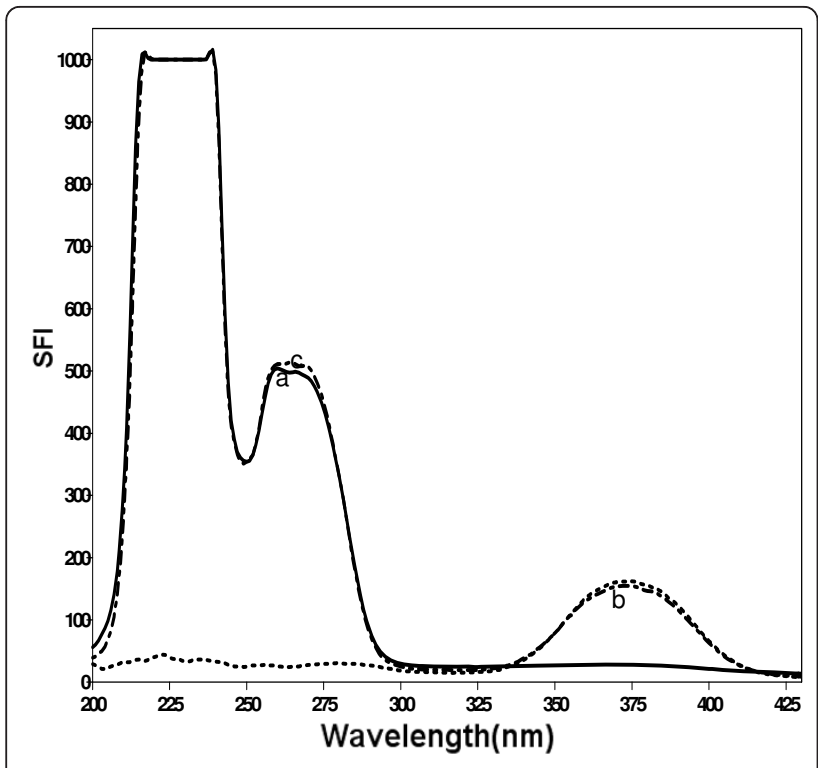

Figure 8 synchronous fluorescence spectra of. a, MTP $(8 \mu \mathrm{g} / \mathrm{mL})$; b, FDP $(0.8 \mu \mathrm{g} / \mathrm{mL}) ;$, synthetic mixture of MTP $(8 \mu \mathrm{g} / \mathrm{mL})$ and FDP $(0.8 \mu \mathrm{g} / \mathrm{mL})$

The proposed method was applied to the simultaneous determination of MTP with FDP in synthetic mixtures containing different concentrations of both drugs in a ratio of 10:1 (Figure 8). The relative synchronous fluorescence intensities were measured for both drugs. The RSFI of MTP was measured at $260 \mathrm{~nm}$ where FDP shows nil contribution, similarly, the RFSI for FDP was measured at $375 \mathrm{~nm}$ where MTP shows nil contribution. The concentrations of both drugs in the synthetic mixture were calculated according to the linear regression equation of the calibration graphs. The results indicate high accuracy of the proposed method as shown in Table 3.

The method was assessed regarding precision by evaluating repeatability and intermediate precision.
- Repeatability: The repeatability was performed by applying the proposed methods for the determination of three concentrations of MTP and FDP in pure forms on three successive times, and the results are listed in Table 4.

- Intermediate precision: Intermediate precision was evaluated through repeated analysis of MTP and FDP in pure form applying the proposed method, using the concentrations showed in Table 4 for a period of 3 successive days.

\section{Selectivity}

The proposed SFS method allowed the selective determination of each drug in presence of the other without any interference proving its selectivity and ability to resolve a mixture of the two drugs.

The proposed method was found to be specific for the two studied drugs in their combined tablets without interference from common tablet excipients such as Titanium oxide, Iron oxide, anhydrous lactose, propyl gallate, colloidal silicon dioxide, paraffin, hypromellose, cellulose, hydroxyl propyl cellulose sodium aluminum silicate, macrogel, sodium stearyl fumarate and poloxyl 40-hydrogenated caster oil. These matrix components did not interfere with the proposed method.

\section{Pharmaceutical Applications}

The proposed method was applied to the determination of the studied drugs in their coformulated tablet Logi$\max ^{\circledR}$. It is a film coated slow release enteric tablet. As most of the analytes and tablet excipients were insoluble in water and soluble in methanol, a solution containing methanol was necessary to dilute drugs and insure for tablet disintegration [4]. Acrodisc GHP was used to ultra clean the extract of particles $0.45 \mu \mathrm{m}$ or larger [4]. The specificity of the method was investigated by observing no interference encountered from the common

Table 3 Application of the proposed method for determination of the studied drugs in their synthetic mixtures.

\begin{tabular}{|c|c|c|c|c|c|c|}
\hline \multirow[t]{2}{*}{ Sample } & \multicolumn{2}{|c|}{ Concentration taken $(\mu \mathrm{g} / \mathrm{mL})$} & \multicolumn{2}{|c|}{ Concentration found $(\mu \mathrm{g} / \mathrm{mL})$} & \multicolumn{2}{|c|}{ Recovery \% } \\
\hline & MTP & FDP & MTP & FDP & MTP & FDP \\
\hline \multirow[t]{3}{*}{ MTP and FDP mixture } & 5.0 & 0.5 & 4.987 & 0.494 & 99.73 & 98.72 \\
\hline & 8.0 & 0.8 & 7.942 & 0.796 & 99.27 & 99.56 \\
\hline & 10.0 & 1.0 & 9.931 & 0.982 & 99.31 & 98.2 \\
\hline$x$ & & & & & 99.44 & 98.83 \\
\hline$\pm \mathrm{SD}$ & & & & & \pm 0.255 & \pm 0.686 \\
\hline$\%$ RSD & & & & & 0.256 & 0.694 \\
\hline$\%$ Error & & & & & 0.148 & 0.401 \\
\hline
\end{tabular}

Each result is the average of three separate determinations. 
Table 4 Validation of the proposed method for determination of MTP and FDP raw materials using SSF mode

\begin{tabular}{cccc}
\hline Concentration added $(\boldsymbol{\mu g} / \mathrm{ml})$ & \% Found & $\%$ RSD & \% Error \\
\hline $\begin{array}{c}\text { MTP } \\
\text { Repeatability }\end{array}$ & & & \\
5.0 & $99.96 \pm 1.73$ & 1.73 & 1.00 \\
8.0 & $100.09 \pm 1.75$ & 1.75 & 1.01 \\
10.0 & $100.02 \pm 0.22$ & 0.22 & 0.13 \\
Intermediate precision & & & \\
5.0 & $99.66 \pm 1.64$ & 1.65 & 0.95 \\
8.0 & $100.09 \pm 1.00$ & 1.00 & 0.58 \\
10.0 & $100.05 \pm 0.68$ & 0.68 & 0.39 \\
FDP & & & \\
Repeatability & & & \\
0.5 & $100.10 \pm 1.57$ & 1.57 & 0.90 \\
0.8 & $100.07 \pm 1.52$ & 1.51 & 0.87 \\
1.0 & $100.23 \pm 1.45$ & 1.45 & 0.83 \\
0.5 & & & \\
0.8 & $99.79 \pm 1.31$ & 1.31 & 0.76 \\
1.0 & $100.36 \pm 0.91$ & 0.90 & 0.52 \\
Intermediate precision & $100.06 \pm 1.62$ & 1.62 & 0.93 \\
\hline
\end{tabular}

Each result is the average of three separate determinations.

excipients. This was proved by good recovery values obtained during determination of MTP and FDP in Logimax ${ }^{\circledR}$ tablets (Table 5).

\section{Conclusion}

A new simple and sensitive method was explored for the simultaneous determination of MTP and FDP in binary mixture. The synchronous spectrofluorometric method, by virtue of its high sensitivity, could be applied to the analysis of both drugs in their co-formulated dosage forms. It was possible to measure low concentrations as
0.32 and $0.06 \mu \mathrm{g} / \mathrm{mL}$ for MTP and FDP respectively with good accuracy. Moreover, synchronous spectrofluorimetric technique enables the determination of MTP in the presence of FDP and vice versa. Moreover, the proposed method is time saving.

\section{Authors' contributions}

MIW designed the proposed method and analyzed the data statistically. FFB proposed, planned and supervised the whole work. NME coordinated the study and modified the text. MHE carried out the experimental work. All authors read and approved the final manuscript.

\section{Competing interests}

The authors declare that they have no competing interests.

Received: 30 July 2011 Accepted: 7 November 2011

Published: 7 November 2011

\section{References}

1. Sweetman SC: Martindale, The Complete Drug Reference. 36 edition. The Pharmaceutical Press: London; 2009, 1285-1286, 1338.

2. United States Pharmacopeial Convention: The United States Pharmacopoeid 30th and The National Formulary 25th Rockville, MD, USA; 2007, Electronic Version.

3. Salem H, Abdallah OM: Determination of Metoprolol and Felodipine in Binary Mixture Using Chemometric-Assisted Spectrophotometric and High-Performance Liquid Chromatographic-UV Methods. Am J App Sci 2007, 4(9):709-717.

4. Rontogianni MA, Markopoulou CK, Koundourellis JE: HPLC and Chemometrically-Assisted Spectrophotometric Estimation of Two Binary Mixtures for Combined Hypertension Therapy. I Liq Chromatogr Relat Tech 2006, 29(18):2701-2719.

5. Wen-Gang W, Liu-Hong Y, Rui W, Xiao-Qing Z: Simultaneous Determination of Metoprolol Tartrate and Felodipine in Skin Diffuse Solution by HPLC. Chin Pharm J 2006, 41:143-146.

6. Zhang Y, Wu H, Xia A, Zhu S, Han Q, Yu R: Fluorescence determination of metoprolol in human plasma by trilinear decomposition-based calibration techniques. Anal Bioanal Chem 2006, 386(6):1741-1748.

7. El Yazbi FA, Mahrous ME, Hammud HH, Sonji GM, Sonji NM: Comparative spectrophotometric, spectrofluorometric, and high performance liquid chromatographic study for the quantitative determination of the binary mixture felodipine and ramipril in pharmaceutical formulations. Anal Lett 2008, 41:853-870.

Table 5 Application of the proposed method for determination of the studied drugs in their co-formulated preparation

\begin{tabular}{|c|c|c|c|c|c|c|c|c|}
\hline \multirow[t]{2}{*}{ Preparation } & \multicolumn{2}{|c|}{$\begin{array}{l}\text { Concentration taken }(\mu \mathrm{g} / \\
\mathrm{mL})\end{array}$} & \multicolumn{2}{|c|}{$\begin{array}{l}\text { Concentration found }(\mu \mathrm{g} / \\
\mathrm{mL})\end{array}$} & \multicolumn{2}{|c|}{ Recovery \% } & \multicolumn{2}{|c|}{$\begin{array}{l}\text { Comparison method } \\
\text { (4) }\end{array}$} \\
\hline & MTP & FDP & MTP & FDP & MTP & FDP & MTP & FDP \\
\hline Logimax $^{\circledR}$ Tablets $^{\mathrm{a}}$ & 5.0 & 0.5 & 4.919 & 0.503 & 98.37 & 100.62 & 98.82 & 99.36 \\
\hline (MTP 50 mg + FDP 5 mg/Tablet) & 8.0 & 0.8 & 7.927 & 0.813 & 99.09 & 101.65 & 101.79 & 100.84 \\
\hline Batch \# 604346 & 10.0 & 1.0 & 9.907 & 1.002 & 99.07 & 100.17 & 99.28 & 99.69 \\
\hline$(x)$ & & & & & 98.84 & 100.81 & 99.96 & 99.96 \\
\hline$\pm \mathrm{SD}$ & & & & & \pm 0.41 & \pm 0.759 & \pm 1.6 & \pm 0.78 \\
\hline$\%$ RSD & & & & & 0.415 & 0.753 & & \\
\hline$\%$ Error & & & & & 0.24 & 0.435 & & \\
\hline $\mathrm{t}$ & & & & & $1.18(2.78)$ & $1.36(2.78)$ & & \\
\hline $\mathrm{F}$ & & & & & $15.2(19)$ & 1.05 (19) & & \\
\hline
\end{tabular}

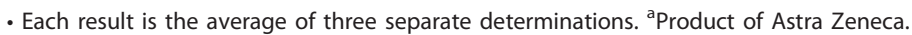

- Figures between parenthesis are the tabulated $t$ (at degree of freedom $=4$ for both drugs) and $F$ values (at degree of freedom $=2,2$ for both drugs), respectively at $p=0.05$ [11]. 
8. Chen GZ, Huang XZ, Xu JG, Zheng ZZ, Wang ZB: The Methods of Fluorescence Analysis. Science Press, Beijing;, 2 1990, 112.

9. Patra D, Mishra AK: Recent development in multicomponent synchronous fluorescence scan analysis. Trends Anal Chem 2002, 21:787-798.

10. Guidance for Industry; Q2B Validation of Analytical Procedures: Methodology. International Conference on Hormonization (ICH). 1996 [http://www.fda.gov/downloads/Drugs/

GuidanceComplianceRegulatoryInformation/Guidances/ucm073384.pdf], (accessed September 1, 2004).

11. Miller JC, Miller JN: Statistics and Chemometrics for Analytical Chemistry. 5 edition. Prentice Hall, England; 2005, 39-73, 107-149, 256

doi:10.1186/1752-153X-5-70

Cite this article as: Walash et al.: Synchronous fluorescence

spectrofluorimetric method for the simultaneous determination of

metoprolol and felodipine in combined pharmaceutical preparation.

Chemistry Central Journal 2011 5:70.

\section{Publish with ChemistryCentral and every scientist can read your work free of charge}

"Open access provides opportunities to our colleagues in other parts of the globe, by allowing anyone to view the content free of charge."

W. Jeffery Hurst, The Hershey Company.

- available free of charge to the entire scientific community

- peer reviewed and published immediately upon acceptance

- cited in PubMed and archived on PubMed Central

- yours - you keep the copyright

Submit your manuscript here:

http://www.chemistrycentral.com/manuscript/<smiles>c1ccccc1</smiles> 